\title{
A Dynamic Model of Mentoring for Hospitality Leadership Development
}

\author{
Lori J. Sipe, Mark Testa \\ San Diego State University, San Diego, CA, USA \\ Email:1sipe@sdsu.edu,mtesta@mindspring.com
}

How to cite this paper: Sipe, L. J., \& Testa, M. (2020). A Dynamic Model of Mentoring for Hospitality Leadership Development. Open Journal of Leadership, 9, 11-33. https://doi.org/10.4236/oj1.2020.91002

Received: September 12, 2019

Accepted: February 9, 2020

Published: February 12, 2020

Copyright $\odot 2020$ by author(s) and Scientific Research Publishing Inc. This work is licensed under the Creative Commons Attribution International License (CC BY 4.0).

http://creativecommons.org/licenses/by/4.0/

\begin{abstract}
Mentoring programs have become mainstay methods of developing leadership skills in the hospitality and tourism context. The following provides the theoretical foundation and overview of a mentoring program implemented for a blended graduate hospitality management program. This provides a model for others seeking to create hybrid mentoring for leadership development. Through structured reflection assignments and industry mentors, the Mentor EDGE program has countered many of the potential drawbacks of traditional mentoring programs, particularly in the online space.
\end{abstract}

\section{Keywords}

Mentoring, Leadership Development, Distance Education, Reflection

\section{Introduction}

Leadership development has become a central focus in hospitality management and education (Testa \& Sipe, 2012) both in the US and across the globe (Lueng, Wen, \& Jiang, 2018). Indeed, a review of necessary skills in the hospitality arena provided by Alhelalat (2015) centers on leadership skills and their prevalence in hospitality management schools. For these schools, finding innovative, experiential and active methods of developing young leaders remains a challenge. One common method of developing young leaders is the implementation of a mentoring program (Kaur, 2015). These programs can take a variety of forms, but the goal is to provide a feedback mechanism for the protégé as they engage in a variety of challenges. Senior leaders provide counsel and seek to assist protégé's in their development. These programs yield significant and positive results such as career advancement, increased self-awareness and leadership development (Eby, Allen, Evans, Ng, \& DuBois, 2008). 
At the same time, mentoring programs can be challenging to implement particularly in the distance education space where little face-to-face contact takes place between students and the program. Online education is at its best when students have regular interaction and opportunities for collaboration. This is contrary to the "first generation" of e-learning which dominates much online education, which is very much a linear and passive process (Adams \& Morgan, 2007). Consequently, hospitality educators are faced with a variety of questions in terms of organization and execution of a successful mentoring program, especially regarding logistics and consistency. Will a directive or non-directive (Klasen \& Clutterbuck, 2002) method be used? Will the mentors be selected for the students, or will the relationship develop organically? If they are selected by the institution, how will compatibility be monitored and managed? Finally, how will consistency in the experience for each pairing be ensured?

The purpose of this paper is to overview an innovative mentoring program we call Mentor EDGE, designed and implemented as part of a blended Masters degree in hospitality leadership at a large public university in California. The first section discusses the theoretical foundations that guided the initial program design to include leadership development theory, distance learning, and mentoring. In the second section of the paper, we examine the Mentor EDGE component of the program in detail, highlighting the design principles in action and the challenges of implementing personalized, experiential leader development for graduate students. Section three of the paper summarizes the results of two iterations of the Mentor EDGE program. Feedback from students, mentors, and faculty is presented as well as the changes implemented in response to this feedback. Finally, we provide a discussion section that highlights key theoretical principles in action alongside our own learning and process of continuous improvement. The paper concludes with implications for the advancement of leader development, distance education, and mentoring theory.

\section{Theoretical Background}

\subsection{Leadership Development Theory}

Leadership development is the process of preparing individuals and collectives to effectively engage in leader-follower interactions (Day \& Dragoni, 2015). In the workplace, leader development has focused on developing managers to be effective in their role as leaders (DeRue \& Myers, 2014). Models of leader development focus on behaviors that enhance leadership competencies as well as expanding one's conceptual frames about the conduct of leadership (Boyce, Zaccaro, \& Wisecarver, 2007). At the heart of any leader development program is transformation and change; it's about altering one's worldview, which leads to changed behavior. Traditional modes of instruction and pedagogies used in management programs, even at the graduate level, are unlikely to bring about this kind of transformational learning (Kuechler \& Stedham, 2018). Hence, we considered four relevant concepts of leadership development theory when de- 
signing the instructional innovation discussed in this paper; competency models, leader self-development, experiential learning, and feedback and reflection.

\section{Competency Models}

Organizations engage in leadership development to achieve strategic objectives and develop internal talent. Many companies anchor their leadership development efforts to competency models they use for recruitment, compensation, and succession planning (McCauley, 2008). Research based models of leadership competencies reflect the needs of contemporary organizations as well as emergent leadership theories. Competency categories comprise managerial skills like problem solving and decision-making (Northouse, 2013), behaviors needed to lead others like visioning and communication (Kaur, 2015), and factors of emotional intelligence like self-awareness and regulation (Boyatzis, 2006). Competency based approaches to management education are fueled by the importance of graduates who can put theory into practice (Testa \& Sipe, 2012).

\section{Leader Self Development}

Competency models provide descriptions of desired outcomes, but research also illuminates the importance of choice and personalization in adult development. Leader self-development stresses that leaders have control over their learning. Rather than being guided by an instructor's syllabus or following prescribed work assignments, the learner determines which activities to engage in. Development begins with the leader creating goals that are personally meaningful (Reichard \& Johnson, 2011). Although the learner is in control, leadership development does not occur in a vacuum. Groups and other relational influences can impede or facilitate one's development (DeRue \& Myers, 2014).

The notion of a personalized yet systematic approach is consistent with intentional change theory introduced by Boyatzis (2006). Based on longitudinal studies of MBA students, Boyatzis outlined an iterative cycle of discoveries that produce sustainable change at the individual level. The process begins with a vision of the ideal self and a personal vision. A comparison of the real self with the personalized vision results in a personal balance sheet of one's strengths and weaknesses. From that self-assessment, a learning agenda and plan is created. The individual experiments and practices with new behaviors, attitudes, and feelings. Each of these steps, according to the author, is influenced by trusted and resonant relationships and feedback (pg. 613).

\section{Experiential Learning}

As indicated, sustainable change is a holistic and continuous process of experimentation and adaptation. Not surprising, emerging research reflects the notion that a high proportion of leadership development should be the result of learning from experience. In educational spaces, experiential learning is based on the concept of self-efficacy (Bandura, 1989). Essentially, within an educational context, students are more likely to believe they can complete a task successfully once they have had personal experiences within their specific field of study. Kolb unpacked the notion of experiential learning by describing four phases of 
the learning cycle. Concrete experiences are tangible events you can physically take part in actively or passively. Reflective observation follows with a focus on what was learned from the concrete experience. Abstract conceptualization refers to thinking about the concrete experience in hopes of gaining new understanding. Active experimentation occurs when the individual applies what they have learned in their surrounding environment outside the confines of a classroom. Central to Kolb's theory is the recognition that learning is not only knowledge based, but requires the integration of the whole person, utilizing action, reflection, thinking, and feeling (Kolb \& Kolb, 2005).

Experience-driven leadership development has been gaining in popularity in recent years. In the workplace, this refers to developing leaders through challenging assignments and projects on the job as opposed to formal leadership training. The term "70-20-10" has been popularized in practitioner literature to suggest that $70 \%$ of leader development should be embedded on the job, $20 \%$ should emphasize relationships, and 10\% should occur through formal training (McCauley, DeRue, Yost, \& Taylor, 2014). Although this stream of research is still in its infancy, stretch assignments, job rotation, cross-functional team projects, and action research are touted as particularly effective in developing leaders on the job (Hezlett, 2016).

\section{Feedback and Reflection}

Experience driven leadership development will be enhanced by ongoing opportunities for feedback and reflection. Reflective thinking enhances self-awareness and increases the likelihood of learning transfer (Reichard \& Johnson, 2011). In workplace studies, reflecting on experiences has been linked to gains in self-efficacy, changes in interpersonal behavior, and improved future performance (DeRue \& Myers, 2014). Some research findings indicate that behavioral and affective changes in emerging leaders are heightened when reflection is guided or structured by action research coaches (Volz-Peacock, Carson, \& Marquardt, 2016). Learning from others and getting feedback along the leadership development journey is also important. Feedback seeking behaviors are valuable for assessing strengths and weaknesses, which ultimately influences subsequent behavior and decision-making (Taylor \& Hood, 2011).

\subsection{Distance Learning}

While there is clear value in utilizing competencies, self-development, experiential learning and feedback in graduate education, doing so through an online platform creates unique difficulties. Online courses in management programs have been steadily increasing in the United States and Europe for the past decade (Arbaugh, 2014). Comparative studies have concluded, for the most part, that online instruction can be as effective as traditional classroom teaching (US Department of Education, 2009). Researchers and faculty are quick to point out, however, that engaging students in distance learning, especially in the development of soft skills, is not without its challenges. Online learning is optimal when 
it involves a high degree of interaction and collaboration (Redpath, 2012). In response, instructional models have evolved from a technology driven, instructor-controlled mindset, to a pedagogy driven, learner in control mindset. For example, Adams \& Morgan (2007) theorized the characteristics and design principles of second generation e-learning to support soft-skill development in leadership education to include:

- Pedagogy driven, facilitated by technology.

- Integrates theory/practice/work/learning in real time.

- Network of interconnected learning opportunities.

- Encourages the learner to bring personal contexts to the learning.

- Evaluation based on self-assessment, reflective practice, and application.

Empirical studies of online management education operationalized constructs from the collaborative inquiry framework (Col) - teaching presence, cognitive presence, and social presence-as potential drivers of enhanced online learning. Teaching presence involves course design, facilitation, and instruction. Cognitive presence is the ability to construct knowledge and meaning through communication. And social presence comprises development of interpersonal relationships, group cohesion, and identification with the community (Redpath, 2012). For example, a recent study of 48 online MBA courses concluded that social presence significantly predicted improvement in grades, student perceptions of learning, and course evaluation. The author suggested that faculty play a key role in cultivating social presence, which he articulated as learners sharing personal feelings and beliefs as well as guided, open communication. He also encouraged program directors to incorporate cohorts and on-site common experiences to drive community identity (Arbaugh, 2014).

\subsection{Mentoring}

Mentoring is considered an effective vehicle to guide and facilitate development and change in programs like hospitality that emphasize industry involvement and applied learning. Mentoring has gained significant modern-day popularity (Spence \& Hyams-Ssekasi, 2015), but also has a rich history dating back to early apprenticeship models (Roberts, 2000). It wasn't until the 1980s that scholars focused on crafting clear and useful definitions of the construct and more formal approaches were developed, particularly in a seminal work by Kathy Kram (1983), where many of the modern conceptualizations stem. Kram identified mentoring as an intense relationship whereby a more experienced individual acted as both a support mechanism and a role model for career-oriented behaviors.

The past 25 years have provided many new distinctions and contextual factors in definitions of mentoring. For example, Cutterbuck (2001) used the term "developmental mentoring" in some contexts which is defined as "help by one person to another in making significant transitions in knowledge, work, or thinking" (Cutterbuck, 2001: p. 3). For the purposes of this paper, mentoring is a 
based on the transmission of knowledge, social capital and psychosocial support (Kaur, 2015). The mentor is generally a wise and trusted individual who utilizes his or her experience in an effort to develop a "mentee" or protégé.

Past research on mentoring suggests that protégés benefit significantly from the process. A study by Freedman (2009) (largely drawing from Kram, 1985) noted that protégés yield both career benefits and psycho-social benefits. In terms of career, mentees enjoy greater job satisfaction, and career contentment as a result of the process. Allen et al. (2004) note that professional benefits extend to greater opportunity for promotion, increased salaries and reduced turnover. This is the direct result of a safe and non-threatening relationship developed with the mentor.

In terms of psycho-social benefits, mentees feel more supported, accepted, recognized and a sense of companionship which may lead to increased confidence. Gannon and Maher (2012) note that more long-lasting relationships may emerge from what begins as a mentoring relationship. The positive relationship and goodwill developed between mentor and mentee may extend to the organization in terms of prosocial behavior (Allen et al., 2004). Selfless behavior often impacts personal satisfaction, increased interpersonal skills and an enhanced ability to reflect. It is important to note that not all scholars see mentoring as a positive construct. Early work by Woodd (1997) noted that the subservient role played by the mentee changes the power dynamics of the duo. Mentees may feel less empowered and less collaborative as a result. Other suggest that mentoring can go wrong when matches are not carefully planned, role or gender conflicts emerge or either the mentor or mentee cannot commit to the relationship as needed (Carr \& Heiden, 2011; McClelland, 2009). Such potential negatives highlight the need for a mentoring process that ensures appropriate matching as well as clear expectations of both participants.

Both informal and formal mentoring processes can take place. Informal mentoring is traditionally spontaneous and organic (Pinho, Coetzee, \& Schreuder, 2005). These relationships are negotiated by the participants and are generally desired relationships rather than mandated relationships. Formal mentoring refers to processes where organizations choose mentors for less experienced individuals (Pinho, Coetzee, \& Schreuder, 2005). Roles are clearly defined in this formal relationship, as is a timeline, means of contact and expectations. Even within the scope of formal mentoring relationships, varying levels of organization, structure and consistency can result. In some cases, meetings are driven by the mentor, some by the mentee and others by the organization. Clarity on meeting structure seems a significant factor for a successful mentoring process (Spence \& Hyams-Ssekasi, 2015).

It seems clear that the level of structure can have implications for how prepared mentors and mentees are and perhaps how committed. If a mentor lacks focus, engagement or time, the relationship is less likely to be beneficial and could impact the level of satisfaction of both parties. This raises a critical factor 
in formal mentoring which is matching mentors and mentees (Gannon \& Maher, 2012). When a "good" match happens, a more positive experience results. Conversely, where a poor match takes place, significant dissatisfaction can result (Fleck \& Mullins, 2012). Ideally, mentors and mentees can select themselves, however this is not always possible (Scandura \& Williams, 2002). It seems likely however that a relationship exists between the level of structure of the mentoring program and the matching process that is used.

In the educational context, this process can exist between faculty and student, administrator and student, or student and student. In some cases, industry professionals are used to guide students as they explore their career and seek to develop their competencies (Spence \& Hyams-Ssekasi, 2015). Industry professionals see mentoring as a process of giving back while deep into a successful career. Such professionals are able to provide a real world perspective that may be more difficult with faculty mentors. This may directly relate to increased skills and employability (Spence \& Hyams-Ssekasi, 2015).

Mentoring, while a complex process, was considered the ideal vehicle, utilizing and maximizing the four central themes of the proposed framework, namely: competency models, self-development, experiential learning, and feedback and reflection. The following illustrates how these four constructs are synthesized in a comprehensive education and mentoring model for use in the online space.

\section{The Mentor Edge Program}

"In times of changes, learners inherit the earth, while the learned find themselves beautifully equipped to deal with a world that no longer exists"

Eric Hoffler

In this section, we discuss the design and implementation of the instructional innovation we call Mentor EDGE. First, we provide a brief overview of the graduate program implemented in 2012 to include a research-based competency model and blended approach to curriculum delivery. Then, we examine the Mentor EDGE component of the program in detail, highlighting design principles in action and the challenges of implementing personalized, experiential leader development for graduate students.

\subsection{The Master of Management in Hospitality and Tourism-Program Overview}

The School of Hospitality and Tourism Management is part of a large, public university in California with annual enrollment exceeding 35,000 students. The School of HTM has offered bachelor's degrees in hospitality, tourism, and recreation since 2001, and its graduates serve the industry needs locally, nationally, and abroad. In 2012, we responded to industry advisors and added a graduate program to hone the leadership and business skills of their seasoned talent and up-and-coming leaders. The design of the HTM Master's program was based on a research initiative that included 110 interviews with hospitality and 
tourism executives and a follow up survey of 352 current business unit managers. The results comprised more than 100 skills and behaviors in 20 competency areas of successful leaders in the hospitality and tourism context. Three broad clusters of competencies-context mastery, relationship mastery, and self-masteryform the foundation of the educational experiences and guide program and course level assessment activities. As summarized in Table 1, Context Mastery refers to the ability for students to effectively manage and lead in their organizational context. Relationship Mastery refers to the student's ability to develop and maintain meaningful relationships. And Self Mastery refers to the student's ability successfully manage one's self and find ways to increase personal efficacy.

In addition to the input about competencies we received from industry stakeholders, the design of the HTM Masters was influenced by insights from the education and leadership development literature, operational and competitive constraints, and the core values of the faculty to include:

- Working professionals desire flexibility and relevance in their coursework.

- Distance learning is most effective when it is collaborative and integrated.

- Second generation e-learning principles align with the core values of HTM graduate faculty.

- Leader development should be experiential and personalized.

- Transformation and growth occurs over time-feedback and reflection is critical.

Figure 1 provides a summary of the graduate program. Currently, the HTM Masters is an 18 month blended program designed to accommodate 18 - 30 students per cohort. Upon acceptance, students engage in a 360 assessment of the leadership competencies listed in Table 1 as well as a commercial assessment called PRINT (Hertz, 2018). These assessments are administered by a third party research firm and select faculty are trained to interpret the results. An intensive resident week launches the learning experience and a final resident week concludes the program 18 months later. The bulk of the coursework occurs online, with cohorts engaging in two or three courses per semester.

We distinguish four types of courses in the course sequencing strand of Figure 1. Resident weeks take advantage of being face-to-face and building cohesion and social presence. The first resident week is also designed to mirror the

Table 1. Research based model of leadership competencies for the HTM graduate program.

\begin{tabular}{ccc}
\hline Context Mastery & Relationship Mastery & Self Mastery \\
\hline Planning & Interpersonal Communication & Accountability \\
Numberwise & Expressive Service & Professionalism \\
Strategic Decision Making & Team Orientation & Self-Development \\
Innovation & Coaching \& Training & Time Management \\
Systems Thinking & Inspiration & Spirit of Optimism \\
Results Orientation & Cultural Alignment & Change Management \\
Technical Service & Networked & \\
\hline
\end{tabular}


learning platforms used throughout the rest of the program. Students take two directed readings courses, one at the beginning, and one toward the end of the course sequencing. These courses are low technology, but highly personalized. Students read five assigned books, and they respond to a series of essay prompts for each book. Individualized feedback is promptly provided, and deeper levels of reflection are coached as students navigate through the texts. Five online courses include leadership, marketing, finance, innovation, and an elective. The cohort engages in a variety of assignments and deliverables one week at a time throughout each of these scheduled courses. These courses are technology intensive. Although students are engaging at a distance, multiple platforms are used to encourage collaboration. The capstone course is an in-company project. Each student designs and leads a team through an approved project in their own organization. Although the projects are individualized, students engage in a structured process of action research with weekly deliverables. Hence, they are engaging in a similar process, with widely different goals, challenges, and results.

In addition to their coursework, students embark on a personalized journey to enhance their leadership competencies. As depicted in Figure 1, the Mentor EDGE program is not a single course but a leader development program that runs parallel to the coursework throughout the 18-month graduate degree program. The purpose of the Mentor EDGE program is to provide customized, experiential learning and competency development for each student in the HTM Master's cohort. The comprehensive approach encourages students to pursue their own leadership vision as they develop their context, relationship and self-mastery. The researched based HTM EDGE competency model provides the foundation for the program. The student driven touchpoints, dedicated faculty,

COURSE SEQUENCING

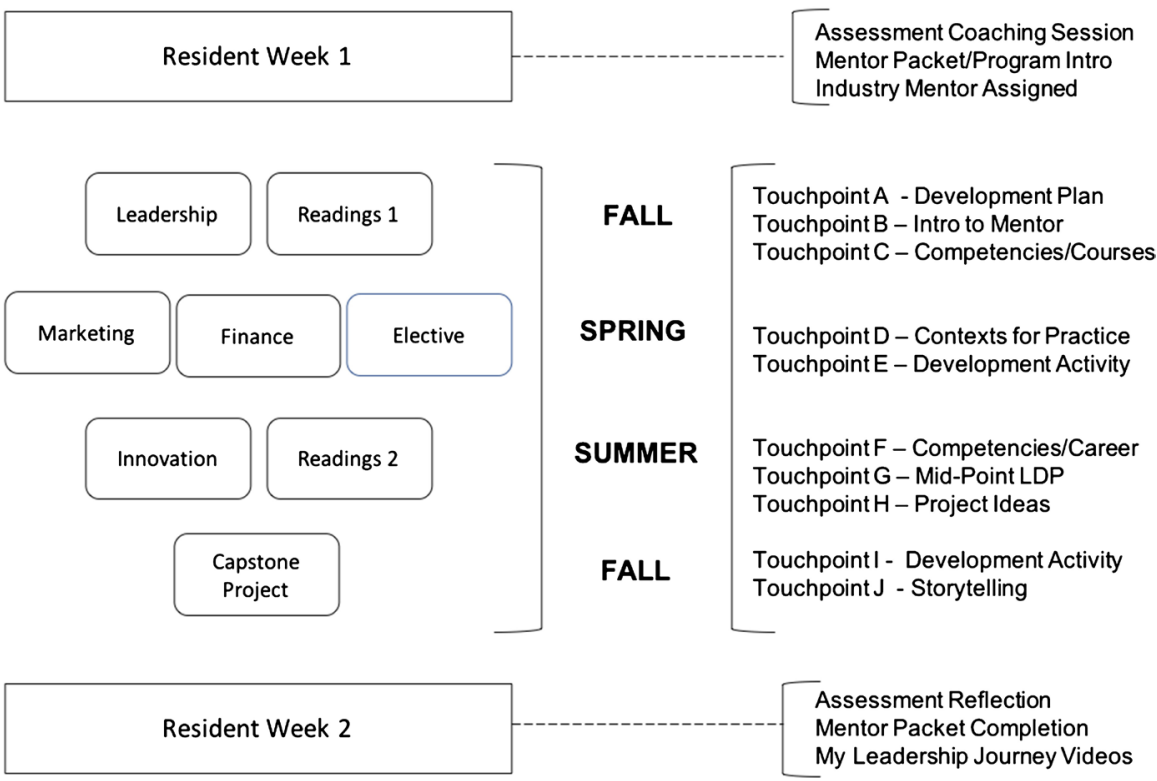

MENTOREDGE PROGRAM

Figure 1. The HTM masters: program overview. 
industry professionals, and the student's own organization offer an unparalleled context for personal transformation.

\subsection{Mentor EDGE Program Design: Leadership Development Theory in Action}

The Mentor EDGE program depicted in Figure 1 aligns with the key leadership development concepts introduced earlier in the paper's theoretical background section. Fueled by a need for graduates with leadership skills that can put theory into practice, a context-specific leadership competency model anchors the program. A commercial firm operationalized the research-based, HTM EDGE competency model (Table 1) and administers a 360 -assessment instrument with each student accepted into the graduate program. Pre-work for the first resident week incudes readings about competency development in general and the role of competency development in the HTM Master's program. A leadership development plan template is introduced as part of the initial resident week. Most importantly, each student receives a two-hour coaching session with a trained faculty member to review and interpret results of their 360 assessment during the resident week. Students synthesize a variety of feedback from their assessments and resident week activities and prepare a leader development plan (LDP) during the first month of coursework. Submission of the completed leader development plan (LDP) is labeled Touchpoint A in Figure 1.

Although the LDP template provides structure, it is not prescriptive. Consistent with contemporary views of leader self-development, the student has control over their own development and is encouraged to engage in activities that are personally meaningful. A vision of the ideal leader alongside the student's assessment of his/her strong and weak competencies drives improvement opportunities. Initially, the student identifies competencies they want to improve and designs mini development activities to practice and reflect. A student guidebook provides sample development activities for each competency to spark idea generation. Ultimately, students are required to show progress toward the goals they created and identified in their LDP, but they are not graded.

Sustainable change is a holistic and continuous process of experimentation and adaption within and outside the required courses. One of the differentiators of the HTM Masters program is its emphasis on experiential learning. Kolb's (1984) theory iterates that knowledge is created through the transformation of one's own experience in context. The HTM Masters also drew from recent research that examines experience driven leadership development in the workplace context (Hezlett, 2016). Throughout the coursework there are assignments that ask students to apply what they have learned to their own organization. Similarly, the Mentor EDGE program recognizes that existing and contingent organizational contexts are important learning "labs". For example, one of the early touchpoint assignments (labeled D in Figure 1) focuses on identifying contexts where students can practice leadership. The impetus is on the student to culti- 
vate their own organizational contexts in ways that will maximize their experiential learning and leadership competency growth.

The importance of feedback and reflection is well established in leadership development literature and is evidenced throughout the Mentor EDGE instructional innovation. Students receive formal and informal feedback throughout the on campus and online courses from faculty, industry, peers, and work stakeholders. As illustrated in Figure 1, this feedback goes beyond assessment of course activities and includes feedback related to the custom EDGE competency model as well as established leadership instruments. Reflective observation refers to the learning process that occurs after participating in a concrete experience (Kolb \& Kolb, 2005). Of particular importance to this phase of learning is the comparison between theoretical understanding of a concept and experiencing the concept in real time. Guided by a series of assignments we call touchpoints, students are asked to synthesize the feedback they receive and reflect on their personal learning and competency development over the course of their degree program. The Mentor EDGE culminates with students sharing their personal journey in a digital story during the final on-campus resident week.

\subsection{Mentor EDGE Implementation}

We were conscious of three "tensions" we would need to navigate as we implemented the Mentor EDGE program. The first consideration involved assessment. Leadership development is a longitudinal process-transformation occurs over time. We needed to assess each student's competency development over an 18 -month journey rather than course by course learning outcomes. A closely related "tension" had to do with the need for continuity and sequencing outside of the typical 3-unit course structure prevalent at the university. Finally, we had to implement a highly personalized program as part of a blended curriculum conducted mostly through online learning. Two key implementation decisionsindustry mentors and structured touchpoints-were most helpful in mitigating the aforementioned "tensions".

The School of Hospitality and Tourism Management already benefits from its deep ties with industry professionals. After seeking input from potential industry mentors, we developed recruitment and training tools outlining the industry mentor's role in implementing the Mentor EDGE program overlay for the graduate program. We summarized the responsibilities of the mentor as providing guidance from an industry professional standpoint, assisting the student in developing leadership competencies, providing feedback and perspective as the student manages work and school. Contrary to other mentor/mentee relationships, we communicated a student-driven process. The student is obligated to take a proactive role in planning meetings and other forms of contact, driving content, sharing information, etc. The mentor is required to understand the basic model we follow as it relates to leadership development (a mentor guidebook is provided), however they do not need to be the driver of any mentoring activi- 
ties. This is a significant departure from traditional mentoring relationships where the mentor leads the process (Cutterbuck, 2005). A reasonable time commitment for mentors is approximately $1-2$ hours per month. The mentor role is primarily a supportive one. There is no grading, no paperwork or other detailed information that mentors need to provide the University.

In order to implement the student-driven relationship and maintain continuity outside formal coursework, a series of short, structured mentor related assignments we called "touchpoints" were developed. Figure 1 lists the timing and focus of each of these touchpoints labeled A through G. The first assignment, Touchpoint A, involves the student sharing their customized leader development plan (LDP) created during their first month in the degree program. Mentors learn about their assigned student's aspirations for leader development, their self-identified strengths and weaknesses, and particular areas they intend to focus their improvement efforts. Another month's structured assignment, Touchpoint F, encourages the student to talk about the integration of their competency development and career. These assignments are intended to provide structure and starting points for continued conversation. They are intentionally designed as mini learning loops of plan-feedback-reflect (Simonin, 2017), with the mentor as the point of intervention. The first page of the touchpoint assignment comprises sections titled purpose, in preparation, and suggested questions/conversations starters/resources. The second page outlines the due date and required deliverables. Most months the deliverable is a summary document comprising five sections-logistics, background, summary of discussion, reflection, and visual. One of the touchpoint assignments, Touchpoint $\mathrm{A}$, is provided as an appendix (Appendix A). A staff member we call the mentor concierge provides support for both the students and mentors. This includes providing contact summary documents to each mentor/student pair, posting mentor touchpoint assignments on the cohort's home page, maintaining a record of completion for each student, and interfacing with the program faculty and director.

\section{Results}

"No plan can see beyond the first engagement. Although it is important to follow the plan, it is equally important to know when and how to modify the plan"

Sun Tzu

Educational design research is typically based on a theoretical framework, but the research aims at designing an intervention in a real-world setting (Anderson \& Shattuck, 2010). Similar to action research, the methodology involves conceptualization, prototyping, implementation, and continued refinement (Pedler, 1983). Our initial goal was to design a leadership development program that mitigated key issues articulated in the literature about distance learning and mentoring. The first iteration of the program was launched in 2012, and it has 
evolved into the Mentor EDGE program depicted in Figure 1. This section examines results from two distinct iterations of the program.

The progression of the program, and in turn the progression of the mentoring program, was based on data collected throughout the process. This data, drawn from students, faculty and mentors, came in from a variety of sources. For students, we looked at the previously described competency assessment, LDP reflections both early in the program and at the end, as well as exit interviews conducted with students as they completed the program. Faculty data came in the form of focus groups conducted during meetings and facilitated debriefs with the Program Director. Finally, mentor data came in the form of debriefs conducted with the mentors and the Program Director to assess program efficacy.

The first two cohorts $(2012,2013)$ had very different experiences than the second three cohorts $(2014,2015,2016)$. As shown in Tables 2-4, perceptions by all three groups differed greatly as the program evolved. From the students' standpoint, the program helped to build a bond with faculty and the cohort, but did not provide a consistent focus on leadership. Since the entire process was done informally, the success of the relationships were also inconsistent. For example, a faculty member focused on tourism might have taken on 4 mentors in the early years versus a one-to-one paring in the more recent program. This stretched the faculty member but also provided less individualized attention on the mentee. Since the student may not have had the same tourism career focus, no common link between the two was ensured. By going to an industry-based model using standardized assignments, leadership development became the center piece of the program. Additionally, the difficulties that might emerge in

Table 2. Student perceptions by cohort.

\begin{tabular}{|c|c|}
\hline Cohorts 1 and 2 & Cohorts 3,4 and 5 \\
\hline $\begin{array}{l}\text { Program Overall } \\
\text { - Personalized and focused on personal growth } \\
\text { - "Faculty Cares" about students } \\
\text { - Cohort Connections were a priority }\end{array}$ & $\begin{array}{l}\text { Program Overall } \\
\text { - Leadership Development was the focus } \\
\text { - Cohort Connections were a priority } \\
\text { - Applicable to any Career }\end{array}$ \\
\hline $\begin{array}{l}\text { LDP Process } \\
\text { - "Gave me a focus on my leadership development" } \\
\text { - Provided a vocabulary to communicate strengths } \\
\text { and weaknesses } \\
\text { - A foundation for competency development } \\
\text { individually based }\end{array}$ & $\begin{array}{l}\text { LDP Process } \\
\text { - Utility of the plan-summarize-reflect } \\
\text { approach in coursework } \\
\text { - Competency development easily } \\
\text { articulated and practiced in their context. }\end{array}$ \\
\hline $\begin{array}{l}\text { Mentors } \\
\text { - Done by faculty in the program. } \\
\text { - Enhanced relationship to the program and faculty } \\
\text { - Matching done by the program director } \\
\text { inconsistently }\end{array}$ & $\begin{array}{l}\text { Mentors } \\
\text { - Integral part of education process } \\
\text { - Trust built over time with an industry } \\
\text { mentor } \\
\text { - Matching done by the program director } \\
\text { based on interest, career focus, experience } \\
\text { level and demographics (Rare issues) }\end{array}$ \\
\hline
\end{tabular}


the pairing process are reduced by the formalization of the touchpoint assignments. The focus was less on the commonality of the mentor-mentee and more on the topics and assignments that became part of the mentoring program.

In the original mentoring program faculty acted as mentors. From this "mentor" standpoint, the initial mentoring program was seen as a method of building greater bonds with students as shown in Table 3 . These bonds would provide support for students as they navigated the challenges of managing an online workload. However, because of the inconsistent matching, some faculty were never completely comfortable in the role of mentor. This lack of confidence can manifest itself in a variety of ways. Faculty not completely understanding the mentee's context might hold back on offering critical advice. Given that a faculty member could have up to 4 mentees, some felt they could not provide the time and energy necessary to do the job at the necessary level. Moving on to the Mentor EDGE phase, mentors were only focused on a single mentee. This mitigated the issue of multiple mentees and a lack of attention. In addition, the structure of the program as previously described allowed the mentee the freedom of focusing on higher-level activities with the student versus determining what to talk about at each meeting. Industry mentors had ample time to review the materials and ask questions of faculty, administration and the concierge before the process began, which helped ensure fewer complications. When there were complications, there was one individual with ownership of the process. Finally, by going to the Mentor EDGE model, the leadership development aspect was highlighted and yielded more consistent interactions with the mentors.

Finally, faculty had varying perceptions of the initial program vs. the Mentor EDGE program as shown in Table 4 . While faculty were initially excited about the prospect of mentoring graduate students, the realities of the workload began to be realized. Put simply, mentoring 3 - 4 students over a year is time consuming. Given the other requirements of a full teaching load, this caused issues for both students and faculty. Perhaps even more concerning was that in the initial mentoring program, there was no grade attached to student efforts. Consequently, a lack of accountability resulted. One challenge of distance education is maintain such accountability with students as the combination of work and school become overwhelming. If there is no grade attached to the program, it is

Table 3. Themes from mentors by cohort.

\begin{tabular}{ll}
\hline Cohorts 1 and 2 & Cohorts 3,4 and 5 \\
\hline - Mentors enjoyed giving back & - Meaningful to see the growth in student \\
- Was a nice way to stay connected & - Industry mentors enjoyed giving back \\
to the program & - Integrated approach is innovative \\
- Matching done by the program & - Matching done by the program director based on interest, \\
director inconsistently & career focus, and demographics (Rare issues) \\
& - Mentors more prepared to work with mentees \\
& - Support person provided to monitor the program provided \\
& a central source of consistent information
\end{tabular}


Table 4. Themes from faculty by cohort.

\begin{tabular}{ll}
\hline Cohorts 1 and 2 & Cohorts 3, 4 and $\mathbf{5}$ \\
\hline - Interactions were meaningful & - Can still engage in informal \\
- Time consuming and took time from teaching and research & "mentoring" \\
- Not linked to a grade which made accountability difficult. & - Students better at reflection \\
- Inconsistent use of the LDP yielded inconsistent experiences & - Learning loops \\
- for students & - Opportunities for integration (i.e. \\
- Varying degree of qualification and commitment by faculty & project) \\
& - Innovative program level \\
& assessment \\
\hline
\end{tabular}

likely the first assignment to be neglected. This was particularly true with the LDP which was part of the mentoring program. Faculty did not use the LDP equally due in some cases to a lack of understanding and in others because of discomfort with the leadership component.

The Mentor EDGE program began with these difficulties in mind. First, a grade was attached to the mentoring program and all corresponding touchpoint assignments. Essentially the mentoring program was a class that overlaid course content. This immediately added gravity to missed assignments or a lack of effort on the part of students. In addition, the built-in feedback, reflection and learning loops enhanced the student's connection to leadership development. Since the feedback was provided by a respected industry person, it carried, in many instances more weight. This feedback was often timelier as a result. With meetings scheduled regularly and in advance, it provided a more consistent vehicle for important industry or leadership advice. Finally, the industry mentor was able to contribute to the student's capstone project at a different level than with faculty. Given the vast amount of experience these professionals had, the feedback had a more practical feel. Students felt confident in the advice they were receiving which positively impacted their final projects. The changes from Cohort 1 and 2 to the Mentor EDGE Program ultimately created a better fit between the mentor and mentee thereby improving the overall experience.

\section{Discussion}

The purpose of this investigation was to overview a dynamic model of mentoring in the distance education space called Mentor EDGE. The theoretical foundations support the use of a leadership competency model, self-development, experiential education and feedback and reflection. By creating a student driving process, moving to industry mentors, and crafting strategically designed touchpoint activities, a more cohesive and consistent leadership development process resulted as indicated by students, faculty and the mentors themselves. Implications exist for such leadership development, distance learning and mentoring.

\subsection{Leadership Development}

The mentoring model developed by the department evolved from an informal faculty-led mentoring process to a highly structured, student-led industry men- 
toring process. As with any new program, growing pains occur and resulted here. However, the lessons learned transformed the program into a center-piece of the degree versus simply an extra set of activities. By creating a student driven process, students take responsibility for their own leadership development. This accountability forces the leadership development message to remain in the student's consciousness throughout the entire program. This was vital in the development process, particularly in the online space where students can become overwhelmed by the workload. Hospitality and tourism educators seeking to create mentoring experiences might do well to consider how students themselves can drive the process. An ancillary benefit of students controlling the process is that industry mentors who are generally busy are more likely to take part in the program. We have had many instances where upon hearing how the students would schedule meetings and that there would be formal topics and assignments, potential mentors were eager to participate.

Rather than "one off" meetings with little structure or connectedness to other assignments, touchpoints allowed us to provide a more consistent learning experience. The level of structure provided in a mentoring program can impact the quality of the experience for both participants (Ehrich, Hansford, \& Tennent, 2004). Those responsible for mentoring programs should consider seeking out more structure in the process as is practicable. In addition, they might consider the timing of the student assignments. Ideally, these assignments match some element of the degree program. For example, in the Mentor EDGE program, touchpoints that take place later in the degree, are directly related to the capstone project. This adds an element of utility to the mentor meetings and tends to be more valuable.

Another implication that can be drawn from the Mentor EDGE program is the value of industry mentors. This is particularly true in the vein of leadership development. Industry professionals who are willing to make the commitment to a student are invaluable. Above and beyond the career development growth that can take place through interaction with the mentor, these professionals become role models for students. Industry mentors can inspire students through their actions but also provide advice that a faculty member, without comparable industry experience could not. In addition, mentors are likely not limited by geography. Given how dispersed students in online programs can be, senior leaders in hospitality and tourism are likely available in most cities and large towns. Again, matching these industry mentors with formal touchpoint assignments was a significant success in the Mentor EDGE program.

\subsection{Distance Learning}

In terms of distance education, the model provided here helps to transition e-learning from what Adams \& Morgan (2007) refer to as the "first generation" to the "second generation". First generation e-learning utilizes early approaches to distance education primarily focused on developing technical skills. This ap- 
proach is characterized by an instructor controlled, linear, technology driven process that views theory separate from practice. Emphasis is placed on visual cues to engage the learner and use separate systems for learning and knowledge capture and dissemination. Clearly there are limitations, just as there were limitations in the educational process before an "adult learner" process was adopted as a mainstream methodology.

The second generation model, which is ideally suited for developing soft skills is far more integrated and pedagogy drives the process. Rather than a linear process, integrated theory and practice is self-organizing and executed in real time. Reflection is a central component of second generation e-learning. It is our hope that applying this approach to a leadership-focused mentoring model helps to contribute to the development of the next tier of distance education. Educators in the hospitality context, particularly in the online space would do well to consider how to apply these second generation concepts their current platform.

\subsection{Mentoring}

With regard to mentoring, the Mentor EDGE model provides some direction for the process. Mentoring is not without challenges as the literature suggests (Cutterbuck, 2005; Gannon \& Maher, 2012; Woodd, 1997). Those either developing or revising their mentoring programs may benefit from reviewing the progression of our model from the first two years of the program to today. San Diego State benefits from having a wide variety and large quantity of potential industry mentors. In smaller cities and towns where the availability may be limited, using the touchpoint approach shown here may help. The structure of the assignments and the student-led nature of the process reduce potential issues with matching mentors and mentees. Because of the prescriptive nature, some of the potential confusion, disorganization, or even power struggles that can emerge in mentoring may be minimized (Spence \& Hyams-Ssekasi, 2015), which may benefit both parties.

In addition, guided reflection as denoted in the Mentor EDGE program provides a vehicle for increased trust between mentor and mentee. Often, mentees can "hide" or remain surface level with their thoughts or emotions. The structured nature of the reflects provides opportunities for mentors and mentees to speak more openly about delicate issues. The result should be a closer relationship between the pair.

\subsection{Overall Significance}

Lastly, the model developed and shown here provides an example of extant theoretical principles of leadership development in action. Educators, particularly those with an applied nature such as Hospitality and Tourism are constantly seeking innovative methods of delivery. We hope that the model of the graduate curriculum provided in Figure 1 and the sample touchpoint in Appendix A help in this regard. No individual model created for one program works perfect- 
ly for another, but certainly these tools may be idea generators.

Additionally, this model may provide some direction for theory building. By overlaying a leadership development model on a graduate distance education program, several opportunities exist for increased social, cognitive and teaching presence. Social presence refers to the sense of connectedness with others in the e-learning space (Dunlap \& Lowenthal, 2014), while cognitive presence is related to the types of deep and relevant cognitive activities used to create understanding (Dunlap et al., 2007). Teaching presence is denoted by using both social and cognitive presence as well as facilitation of communication and interaction among the stakeholders in the online space (Dunlap et al., 2016; Le Roux \& Nagel, 2018). Educators seek to create what Garrison et al. (2000) refer to as Communities of Inquiry by including all three elements in the online space. The relationship developed between the mentor and mentee provides a sense of social prescience. Regular interactions add a richer social context that is often hard to achieve in the online space. By adding the mentoring component, interactions between student-student and student-instructor are complimented, minimizing transactional distance. In terms of cognitive presence, the use of touchpoint assignments with heavy focus on reflection provides this deep level of cognitive-processing.

Each touchpoint and the corresponding reflection provide an opportunity to enhance conceptual understanding. Again, this is more effective when the touchpoints are in sync with the content and requirements of the program. Both social and cognitive presence are planned and facilitated through teaching presence. Teachers use any and all means necessary to maximize the student experience. This includes design and organization, facilitating discourse and direct instruction (Le Roux \& Nagel, 2018). Looking at future research, several questions emerge. For example, how can both social, cognitive and teaching presence processes be enhanced in such mentoring programs? How can hospitality educators build on the initial steps provided here? To what extent can levels of reflection be elevated so that deeper levels of understanding result? These questions are all potential areas of inquiry moving forward.

Another unique characteristic of the Mentor EDGE program that provides opportunity for further research is what we term "mentoring UP". With the student guiding the process described here, there is a potential pathway for increased student leadership. In what ways can students guide more online education as well as traditional learning? What are the limitations of student driven processes in education? Further research may explore these questions and push the boundaries of the student's traditional role.

Finally, there may be opportunities to explore the relationship between leader self-development and leadership development in organizations. Leadership does not take place in a vacuum, nor does leadership development. The context of each learning experience is unique. Consequently, what may work in one organization may not work in another. As a starting point, can the process described 
here be used in hospitality organizations seeking to develop leadership in its ranks? If so, what elements might work and which may need alteration? How does such a process change based on the type of organization? Such questions provide direction for scholars seeking to further enhance leadership in the hospitality and tourism context.

\section{Conclusion}

The theory, process and examples provided here illustrate how a mentoring program, particularly one in a hybrid environment can be developed. What seems clear is that such mentoring programs need to be based on foundational research in the areas of leadership competencies, self development, experiential learning, and feedback and reflection. It is hoped that this is starting point for further refinement of this program and others like it. Only through continued refinement can leadership development efforts be maximized, particularly when today's environment allows for less one-on-one contact.

\section{Conflicts of Interest}

The authors declare no conflicts of interest regarding the publication of this paper.

\section{References}

Adams, J., \& Morgan, G. (2007). “Second Generation” E-Learning: Characteristics and Design Principles for Supporting Management Soft-Skills Development. International Journal on E-Learning, 6, 157-185.

Allen, T. D., Eby, L. T., Poteet, M. L., Lentz, E., \& Lima, L. (2004). Career Benefits Associated with Mentoring for Protégé's: A Meta-Analysis. Journal of Applied Psychology, 89, 127-136. https://doi.org/10.1037/0021-9010.89.1.127

Alhelalat, J. A. (2015). Hospitality and Non-Hospitality Graduate Student Skills between Education and Industry. Journal of Business Studies Quarterly, 6, 46-55.

Anderson, T., \& Shattuck, J. (2010). Design-Based Research: A Decade of Progress in Educational Research? Educational Researcher, 41, 16-25. https://doi.org/10.3102/0013189X11428813

Arbaugh, J. B. (2014). System, Scholar or Students? Which Most Influences Online MBA Course Effectiveness? Journal of Computer Assisted Learning, 30, 349-362. https://doi.org/10.1111/jcal.12048

Bandura, A. (1989). Regulation of Cognitive Processes through Perceived Self-Efficacy. Developmental Psychology, 25, 729. https://doi.org/10.1037/0012-1649.25.5.729

Boyce, L. A., Zaccaro, S. J., \& Wisecarver, M. (2007). Propensity for Self-Development of Leadership Attributes: Understanding, Predicting, and Supporting Performance of Leader Self-Development.

Boyatzis, R. (2006). Intentional Change. Journal of Organizational Excellence, 25, 49-60. https://doi.org/10.1002/joe.20100

Carr, K., \& Heiden, E. P. (2011). Revealing Darkness through Light: Communicatively Managing the Dark Side of Mentoring. Australian Journal of Communication, 38, 89-104.

Cutterbuck, D. (2001). Everyone Needs a Mentor: Fostering Talent at Work. London: 
CIPD.

Cutterbuck, D. (2005). Establishing and Maintaining Mentoring Relationships: An Overview of Mentor and Mentee Competencies. SA Journal of Human Resource Management, 3, 2-9. https://doi.org/10.4102/sajhrm.v3i3.70

Day, D. V., \& Dragoni, L. (2015). Leadership Development: An Outcome-Oriented Review Based on Time and Levels of Analyses. Annual Review of Organizational Psychology and Organizational Behavior, 2, 133-156. https://doi.org/10.1146/annurev-orgpsych-032414-111328

DeRue, D. S., \& Myers, C. G. (2014). Leadership Development: A Review and Agenda for Future Research. In D. V. Day (Ed.), the Oxford Handbook of Leadership and Organizations (pp. 832-855). New York: Oxford University Press. https://doi.org/10.1093/oxfordhb/9780199755615.013.040

Dunlap, J. C., \& Lowenthal, P. R. (2014). The Power of Presence: Our Quest for the Right Mix of Social Presence in Online Courses. In A. A. Piña, \& A. P. Mizell (Eds.), Real Life Distance Education: Case Studies in Practice (pp. 41-66). Greenwich: Information Age Publishers.

Dunlap, J. C., Sobel, D. M., \& Sands, D. (2007). Supporting Students' Cognitive Processing in Online Courses: Designing for Deep and Meaningful Student-to-Content Interactions. TechTrends, 51, 20-31. https://doi.org/10.1007/s11528-007-0052-6

Dunlap, J. C., Verman, G., \& Johnson, H. L. (2016). Presence + Experience: A Framework for the Purposeful Design of Presence in Online Courses. TechTrends, 60, 145-151. https://doi.org/10.1007/s11528-016-0029-4

Eby, L. T., Allen, T. D., Evans, S. C., Ng, T., \& DuBois, D. L. (2008). Does Mentoring Matter? A Multidisciplinary Meta-Analysis Comparing Mentored and Non-Mentored Individuals. Journal of Vocational Behavior, 72, 254-267. https://doi.org/10.1016/j.jvb.2007.04.005

Ehrich, L. C., Hansford, B., \& Tennent, L. (2004). Formal Mentoring Programs in Education and Other Professions: A Review of the Literature. Educational Administration Quarterly, 40, 518-540. https://doi.org/10.1177/0013161X04267118

Fleck, C., \& Mullins, M. E. (2012). Evaluating a Psychology Graduate Student Peer Mentoring Program. Mentoring \& Tutoring: Partnership in Learning, 20, 271-290. https://doi.org/10.1080/13611267.2012.687157

Freedman, S. (2009). Effective Mentoring. IFLA Journal, 35, 171-182. https://doi.org/10.1177/0340035209105672

Garrison, D. R., Anderson, T., \& Archer, W. (2000). Critical Inquiry in a Text-Based Environment: Computer Conferencing in Higher Education. The Internet and Higher Education, 2, 87-105. https://doi.org/10.1016/S1096-7516(00)00016-6

Gannon, J. M., \& Maher, A. (2012). Developing Tomorrow's Talent: The Case of an Undergraduate Mentoring Programme. Education + Training, 54, 440-455. https://doi.org/10.1108/00400911211254244

Hertz, P. (2018). Print. https://www.paulhertzgroup.com

Hezlett, S. A. (2016). Enhancing Experience-Driven Leadership Development. Advances in Developing Human Resources, 18, 369-389. https://doi.org/10.1177/1523422316645887

Kaur, J. (2015). Enhancing Leadership Competencies: Through Mentoring Process. International Journal of Management Research \& Review, 5, 265-269.

Klasen, N., \& Clutterbuck, D. (2002). Implementing Mentoring Schemes, a Practical Guide to Successful Programs. Oxford: Butterworth-Heinemann. 
Kolb, D. (1984). Experiential Learning: Experience as the Source of Learning and Development. Englewood Cliffs, NJ: Prentice Hall.

Kolb, A. Y., \& Kolb, D. A. (2005). Learning Styles and Learning Spaces: Enhancing Experiential Learning in Higher Education. Academy of Management Learning \& Education, 4, 193-212. https://doi.org/10.5465/amle.2005.17268566

Kram, K. E. (1983). Phases of the Mentor Relationship. Academy of Management Journal, 26, 608-625. https://doi.org/10.2307/255910

Kram, K. E. (1985). Mentoring at Work: Developmental Relationships in Organizational Life. Glenview, IL: Scott Foresman.

Kuechler, W., \& Stedham, Y. (2018). Management Education and Transformational Learning: The Integration of Mindfulness in an MBA Course. Journal of Management Education, 4, 8-33. https://doi.org/10.1177/1052562917727797

Le Roux, I., \& Nagel, L. (2018). Seeking the Best Blend for Deep Learning in a Flipped Classroom-Viewing Student Perceptions through the Community of Inquiry Lens. International of Educational Technology in Higher Education, 15, 1-28.

https://doi.org/10.1186/s41239-018-0098-x

Lueng, X. Y., Wen, H., \& Jiang, L. (2018). What Do Hospitality Graduates Learn in Different Countries? An International Comparison of Curriculum. Journal of Hospitality, Leisure, Sport \& Tourism Education, 22, 31-41.

https://doi.org/10.1016/j.jhlste.2018.01.001

McCauley, C. D. (2008). Leader Development: A Review of Research. Greensboro, NC: Center for Creative Leadership.

McCauley, C. D., DeRue, D. S., Yost, P. R., \& Taylor, S. (2014). Experience-Driven Leader Development: Models, Tools, Best Practices, and Advice for On-the-Job Development. Hoboken, NJ: John Wiley \& Sons. https://doi.org/10.1002/9781118918838

McClelland, R. T. (2009). The Dark Side of Mentoring: Explaining Mentor-on-Mentor Aggression. International Journal of Applied Philosophy, 23, 61-86. https://doi.org/10.5840/ijap20092315

Northouse, P. (2013). Leadership: Theory and Practice. Thousand Oaks, CA: Sage Publications.

Pedler, M. (1983). Action Learning in Practice. Aldershot: Gower.

Pinho, S. D. C., Coetzee, M., \& Schreuder, D. (2005). Formal Mentoring: Mentee and Mentor Expectations and Perceived Challenges. SA Journal of Human Resource Management, 3, 20-26. https://doi.org/10.4102/sajhrm.v3i3.72

Redpath, L. (2012). Confronting the Bias against On-Line Learning in Management Education. Academy of Management Learning and Education, 11, 125-140. https://doi.org/10.5465/amle.2010.0044

Reichard, R. J., \& Johnson, S. K. (2011). Leader Self-Development as Organizational Strategy. The Leadership Quarterly, 22, 33-42. https://doi.org/10.1016/j.leaqua.2010.12.005

Roberts, A. (2000). Mentoring Revisited: A Phenomenological Reading of the Literature. Mentoring \& Tutoring, 8, 145-170. https://doi.org/10.1080/713685524

Scandura, T. A., \& Williams, E. A. (2002). Formal Mentoring: The Promise and the Precipice. In C. L. Cooper, \& R. J. Burke (Eds.), The New World of Work: Challenges and Opportunities (pp. 49-74). Oxford: Blackwell.

Simonin, B. L. (2017). N-Loop Learning: Part I-Of Hedgehog, Fox, Dodo Bird and Sphinx. The Learning Organization, 24, 169-179.

https://doi.org/10.1108/TLO-12-2016-0099 
Spence, S., \& Hyams-Ssekasi, D. (2015). Developing Business Students' Employability Skills through Working in Partnership with a Local Business to Deliver an Undergraduate Mentoring Programme. Higher Education, Skills and Work-Based Learning, 5, 299-314. https://doi.org/10.1108/HESWBL-07-2014-0034

Taylor, S. N., \& Hood, J. N. (2011). It May Not Be What You Think: Gender Differences in Predicting Emotional and Social Competence. Human Relations, 64, 627-652. https://doi.org/10.1177/0018726710387950

Testa, M. R., \& Sipe, L. (2012). Service-Leadership Competencies for Hospitality and Tourism Management. International Journal of Hospitality Management, 31, 648-658. https://doi.org/10.1016/j.ijhm.2011.08.009

US Department of Education (2009). Evaluation of Evidence-Based Practices in On-Line Learning: A Meta-Analysis and Review of On-Line Learning Studies. Washington DC: Office of Planning, Evaluation, and Policy Development.

Volz-Peacock, M., Carson, B., \& Marquardt, M. (2016). Action Learning and Leadership Development. Advances in Developing Human Resources, 18, 318-333. https://doi.org/10.1177/1523422316645884

Woodd, M. (1997). Mentoring in Further and Higher Education: Learning form the Literature. Education and Training, 39, 333-343.

https://doi.org/10.1108/00400919710192368 


\section{INTRODUCTION TO INDUSTY MENTOR MentorEDGE Touchpoint A}

Masters Lounge Cohort \#3

\section{Purpose:}

To initiate the mentor relationship and provide an overview of the MentorEDGE program and the ways you might work together to enhance your leadership competencies

\section{Due Date:}

- Deliverable submitted through the assignments tab in Masters Lounge

- Mentor Concierge will record completed assignments with a score of 1

- Due by Sunday, November 2 at 10:00 p.m.

\section{In Preparation:}

- Read the MentorEDGE Guidebook for Students

- Review your LDP

- Watch the video lecture titled MentorEDGE for Students

- Obtain the contact information for your assigned mentor

- Find out a bit about the mentor organization

- Initiate contact with your mentor and arrange your "touchpoint"

- Suggested amount of contact time is one hour

- Consider the suggested topics of discussion prompts

- Prepare - student driven and conscious of mentor time

\section{Suggested Topics of Discussion:}

- Get to Know Each Other's Backgrounds

- Summarize Your Leadership Development Plan

- Discuss Ways the Mentor Might Assist with First Development Activity

- Review the Schedule at a Glance

- Discuss Ways to Work Together - Preferences

\section{Required Deliverables:}

- A one-page summary document of your touchpoint to include the following sections: Logistics, Background, Summary, Reflection, Visual

- Logistics - Contact information and date and place of touchpoint

- Background - Brief bio of the student, reason for enrolling in the masters, leadership development strengths and weaknesses, and competency gaps

- Summary - Bullet list of topics discussed

- Reflection - Provide insights into your thoughts and feelings before, during. and after the touchpoint. Be open about how your touchpoint influences your leadership development journey. Make connections to other learning experiences.

- Visual - Conclude with some sort of visual representation that conveys the touchpoint. This could be a graphic model, metaphor, photo, quote, etc - a nontraditional way to convey a connection to your written reflection. 